УДК 597.552; 5.59.018

\title{
ФЕНЕТИЧЕСКИЕ ОСОБЕННОСТИ БУРЕИНСКОГО ХАРИУСА THYMALLUS BUREJENSIS (SALMONIDAE): ЧЕРНЫЕ ПЯТНА НА БОКАХ ТЕЛА
}

\author{
Антонов А. Л. \\ ФГБУН Институт водных и экологических проблем \\ Хабаровский федеральный исследовательский центр ДВО РАН, г. Хабаровск \\ E-mail: antonov@ivep.as.khb.ru
}

\begin{abstract}
Исследованы особенности окраски тела буреинского хариуса Thymallus burejensis - черные пятна на левом боку рыб. Впервые получены данные о частоте встречаемости пятен и горизонтальных рядов пятен на различных участках тела; исследованы форма пятен, их размеры и количество. Всего по цветным фотографиям проанализировано 168 особей из рек Буреинского государственного заповедника (140 из р. Правая Бурея и 28 - из р. Левая Бурея, после фотосъемки более $90 \%$ рыб были выпущены) и 19 - из других притоков р. Бурея. У всех рыб пятна обнаружены: 1 - в передней части тела; 2 - позади головы близ cleithrum-supracleithrum; 3 - ниже боковой линии. Общее количество пятен на боку в среднем у рыб из р. Правая Бурея составило 9.6 $\pm 0.4(\mathrm{lim}=1-29)$, из р. Левая Бурея $-9.7 \pm 0.8(\mathrm{lim}=2-20)$. Предполагается, что особи из этих рек представляют единую популяцию, так как статистически значимых различий между ними по анализируемым фенам и фенокомплексам не обнаружено. Установлено также, что количество пятен у разных особей может совпадать, но особенности их расположения, размеры и форма имеют индивидуальный характер. Это в условиях заповедного режима позволяет идентифицировать каждую особь без изъятия из природы, что имеет значение для исследований сезонных миграций, перемещений и выделения локальных популяционных группировок.
\end{abstract}

Ключевые слова: буреинский хариус Thymallus burejensis, фенетика, черные пятна, бассейн р. Бурея.

DOI: $10.34078 / 1814-0998-2020-3-75-82$

Фенетические особенности хариусовых рыб рода Thymallus привлекают внимание исследователей в связи с возможностью использовать фенетические признаки (обычно рисунок на спинном плавнике) для целей таксономии и выявления популяционного разнообразия этих рыб (Световидов, 1936; Зиновьев, Богданов, 1976; Макоедов, 1987, 1999; Пресноводные..., 2001; Книжин и др., 2004; Пустовойт, 2008; Романов и др., 2016). Буреинский хариус Thymallus burejensis Antonov, 2004 - сравнительно недавно описанный, узкоареальный эндемичный вид, обитающий в бассейне верхнего течения р. Бурея (Антонов, 2004, 2012). Особенности его фенетики почти не исследованы. Между тем познание фенетических признаков любого вида и фенетики природных популяций имеет значение для выявления внутривидового разнообразия, мониторинга популяций и их охраны (Яблоков, 1980). В настоящем сообщении впервые представлены количественные и качественные данные по осо-

(C) Антонов А. Л., 2020 бенностям окраски тела (черные пятна на боках) этого вида. Цель работы - выявить основные видовые и индивидуальные особенности расположения пятен на теле рыб, их количество и форму; определить возможность использования этих признаков для выявления индивидуальных различий, а также групповых между особями из разных рек.

\section{МАТЕРИАЛ И МЕТОДЫ}

Ранее при описании вида было отмечено, что у исследованных половозрелых особей на боках между рядами чешуй располагаются черные пятна различной формы в количестве от 3 до 23 (Антонов, 2004). Как показали наши дальнейшие исследования, эти пятна являются одним из характерных признаков этого вида, они есть у всех обследованных рыб; их количество изменяется в более широких пределах, они имеют четкие границы и хорошо заметны (рис. 1). По сравнению с другими видами хариусов, обитающими в бассейне Амура, у которых на теле также имеются черные пятна, размеры пятен у буреинского намного больше, их количество сравнительно неве- 


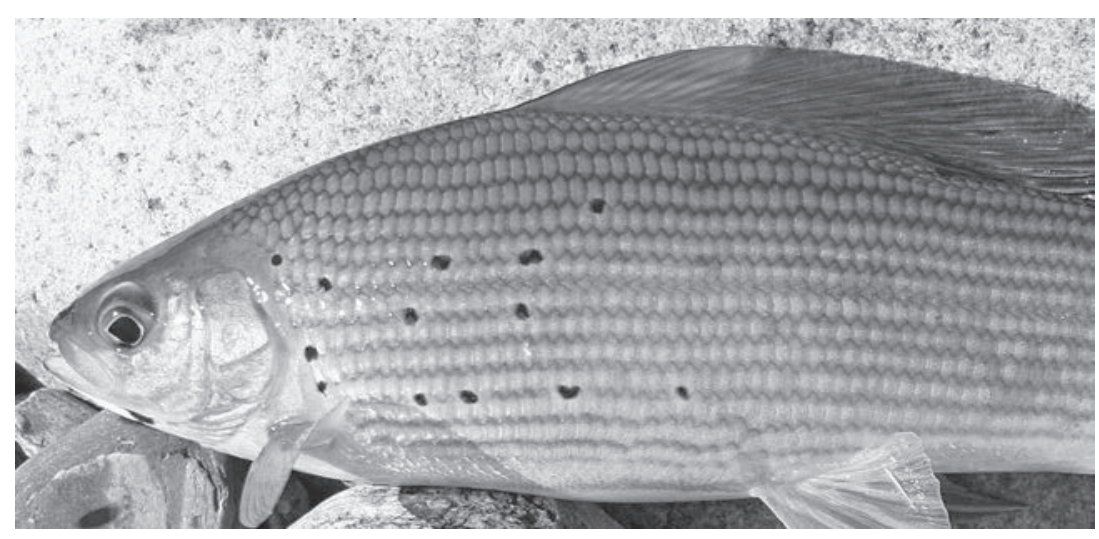

Puc. 1. Черные пятна на левом боку буреинского хариуса. Общее количество пятен -13 ; выше боковой линии -4 ; «в боковой линии» -1 ; ниже боковой линии - 8; позади головы близ cleithrum-supracleithrum 3 ; в т. ч. у cleithrum - 2. Рядов пятен -2 ; выше боковой линии - 1; ниже боковой линии -1

Fig. 1. Black spots on the left side of the Bureya grayling. The total number of spots is 13; above the lateral line - 4; "in the lateral line" - 1; below the lateral line -8 ; behind the head near cleithrum-supracleithrum -3 ; including cleithrum -2 . Rows of spots -2 ; above the the lateral line -1 ; below the the lateral line -1

лико, они дискретны, имеют достаточно четкие границы, что позволяет легко их обнаруживать, подсчитывать и анализировать, т. е. использовать в качестве фенов.

Материалом для настоящего сообщения послужили фотографии рыб, отловленных автором удочкой в бассейне верхнего течения р. Бурея в pр. Правая и Левая Бурея, на территории Буреинского государственного природного заповедника в 2011-2017 гг. Эти реки, сливаясь, образуют р. Бурея; они являются типичными горными, имеют близкие гидрологические параметры; их водосборы расположены на территории заповедника; лишь у р. Левая Бурея небольшая нижняя левобережная часть не входит в его состав. Разнообразие местообитаний выше в р. Левая Бурея - пойма более выражена, здесь больше проток и заломов.

У отловленных рыб фотографировали левый бок фотокамерой Canon-EOS 350 D. Всего было сфотографировано 175 особей (более 90\% рыб после фотосъемки были выпущены), из них проанализировано 168 (140 - из р. Правая Бурея и 28 - из р. Левая Бурея). Рыбы, у которых на фото было трудно определить точное количество пятен и характер их происхождения, в анализ не включены. В выборке более 95\% составляли половозрелые особи, длиной более 30 см по Смитту. Соотношение полов по внешним признакам, в том числе по относительной длине основания спинного плавника и его высоте в задней части, можно оценить как близкое 1:1. Кроме этого, были проанализированы фото рыб этого вида из других, нижерасположенных притоков р. Бурея: из р. Умальта-Макит - 6 экз., из p. Серегекта - 3, из р. Янырь 2 ; из р. Талибджан - 6, из р. Тырма -2 .

При анализе рассматриваемых фенов автор руководствовался основными понятиями и указаниями, изложенными в работах А. В. Яблокова (1980), А. В. Яблокова и Н. И. Лариной (1985) и Л. А. Животовского (1991), поэтому не учитывал пятна, появившиеся у рыб в онтогенезе в результате какихлибо воздействий, т. е. не являющихся фенами. У исследованных особей такие приобретенные пятна хорошо отличаются от пятен-фенов своим цветом (они серые, в отличие от черных пятен-фенов) и особенностями расположения (приобретенные пятна расположены на местах утерянных чешуй и на травмированных участках тела). Кроме этого, выбор анализируемых признаков был сделан с учетом указания Л. А. Животовского (1991) о важности использования как можно большего их количества. На фото были исследованы следующие признаки:

1. Особенности расположения пятен - частота их встречаемости на различных участках тела, в том числе: 1) в передней части туловища - от его начала (от cleithrum-supracleithrum) до вертикали, проходящей через начало основания брюшного плавника; 2) позади головы (близ cleithrumsupracleithrum); 3) на жаберной крышке; 4) в задней части тела - от вертикали, проходящей через начало основания брюшного плавника до конца чешуйного покрова; 5) на хвостовом стебле; 6) «в боковой линии». Непосредственно «в боковой линии», т. е. в ряду, состоящем из прободенных чешуй, пятен не обнаружено, поэтому «в боковой линии» взято в кавычки. Пятна в этой зоне располагаются между боковой линией - т. е. между рядом прободенных чешуй и соседними, выше- или нижележащими рядами непрободенных (рис. 2); 6) выше боковой линии - над 1-3-м рядами чешуй выше боковой линии; 7) ниже боковой линии - под 1-3-м рядами чешуй ниже боковой линии.

2. Частота встречаемости горизонтальных рядов пятен. За ряд принимали фенокомплекс, состоящий из трех пятен и более, находящихся в одном ряду.

3. Форма и размеры пятен.

4. Количество пятен. Их подсчитывали на различных участках тела рыб по следующей схеме: 


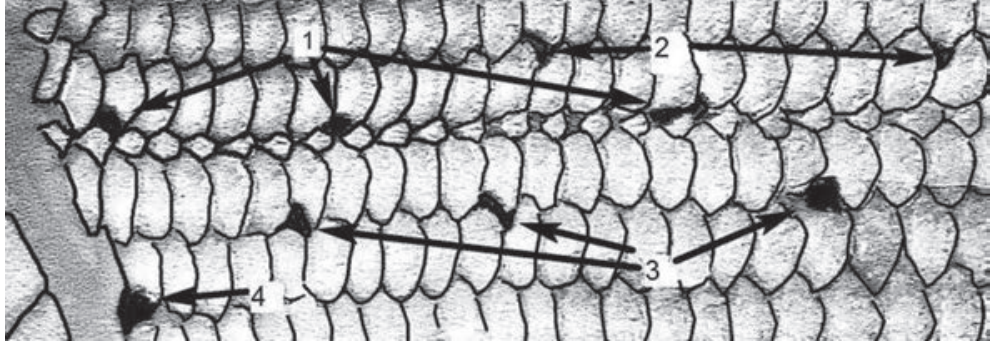

Puc. 2. Некоторые особенности расположения пятен на боку буреинского хариуса: 1 - «в боковой линии»; 2 - выше боковой линии над первым рядом чешуй; 3 - ниже боковой линии под первым рядом чешуй; 4 - ниже боковой линии под вторым рядом чешуй y cleithrum

Fig. 2. Some features of the location of spots on the Bureya grayling side: 1 - "in the lateral line"; 2 - above the lateral line, above the first row of scales; 3 - below the lateral line, under the first row of scales; 4 - below the lateral line, under the second row of scales at cleithrum

1) общее количество пятен на боку; 2) количество пятен «в боковой линии»; 3) количество пятен выше боковой линии; 4) количество пятен ниже боковой линии; 5) количество рядов пятен выше и ниже боковой линии. По этим признакам и по частоте встречаемости пятен на различных участках тела была также предпринята попытка выявить различия у рыб из рр. Правая и Левая Бурея. Статистические расчеты делали по стандартной методике с использованием программы Excel.
Кроме этого, для рыб, имеющих в области границы тела c cleithrum одно пятно, рассчитаны показатель внутрипопуляционного фенетического разнообразия и доля редких морф (Животовский, 1980).

\section{РЕЗУЛЬТАТЫ И ОБСУЖДЕНИЕ}

Особенности расположения пятен. Анализируемые пятна-фены располагаются в коже рыб, между рядами чешуй. При этом пятно может частично находиться под чешуей и, очень редко, полностью под ней (всего отмечены две такие особи, у которых по одному пятну было под чешуей).

У всех обследованных рыб в передней части тела имелись пятна. Также у всех рыб пятна были позади головы близ cleithrum-supracleithrum, в том числе ниже боковой линии. В задней части тела пятна были только у $14.3 \%$ всех рыб. В р. Правая Бурея отловлено 18 таких особей $(12.9 \%)$; в р. Левая Бурея их доля была выше $-21.4 \%$ (табл. 1). Лишь у одной особи (из р. Правая Бурея) одно пятно отмечено на хвостовом стебле. Очень редко пятна встречаются на жаберной крышке.

В пределах «боковой линии» пятна есть у большинства рыб (67.3\%). Выше нее они

Таблица. 1. Частота встречаемости пятен на различных участках тела у обследованных рыб, \% Table 1. Frequency of spots on different parts of the body in the examined fish, $\%$

\begin{tabular}{|l|c|c|c|}
\hline \multicolumn{1}{|c|}{ Участок тела } & Правая Бурея, $\mathrm{n}=140$ & Левая Бурея, $\mathrm{n}=28$ & В целом $\mathrm{n}=168$ \\
\hline 1) в передней части тела & 100 & 100 & 100 \\
\hline 2) в задней части тела & 12.9 & 21.4 & 14.8 \\
\hline 3) на хвостовом стебле & 0.7 & 0 & 0.5 \\
\hline $\begin{array}{l}\text { 4) позади головы (у cleithrum и } \\
\text { supracleithrum) }\end{array}$ & 100 & 100 & 100 \\
$\begin{array}{l}\text { в том числе: } \\
\text { 4.1) «в боковой линии» }\end{array}$ & 59.3 & 50.0 & \\
4.2) выше боковой линии & 22.9 & 28.6 & 57.7 \\
4.3) ниже боковой линии & 100 & 100 & 23.8 \\
\hline 5) «в боковой линии» & 69.3 & 57.1 & 100 \\
\hline 6) выше боковой линии & 92.1 & 96.4 & 67.3 \\
в том числе: & & & 92.9 \\
6.1) над 1-м рядом чешуй & 88.6 & 92.9 & 89.3 \\
6.2) над 2-м рядом чешуй & 5.0 & 10.7 & 6.0 \\
6.3) над 3-м рядом чешуй & 15.7 & 7.1 & 14.3 \\
\hline 7) ниже боковой линии & 100 & 100 & 100 \\
в том числе: & & & 94.0 \\
7.1) под 1-м рядом чешуй & 93.6 & 96.4 & 90.4 \\
7.2) под 2-м рядом чешуй & 91.4 & 85.7 & 3.6 \\
7.3) под 3-м рядом чешуй & 92.9 & 46.4 & \\
\hline 8) на жаберной крышке & 3.6 & 3.6 & \\
\hline
\end{tabular}


встречаются чаще $(92.9 \%)$ и обычно располагаются над 1-м рядом чешуй, реже над 2-м (см. табл. 1). Особи, имеющие пятна над 3-м рядом и выше, не обнаружены. Ниже боковой линии пятна найдены у всех обследованных рыб, при этом они располагаются здесь почти равномерно под 1-3-м рядами чешуй (см. табл. 1) и очень редки под 4-м (2 особи) и 5-м (1 особь).

Между выборками из рр. Правая и Левая Бурея наиболее существенные различия в частоте встречаемости пятен на различных участках тела обнаружены для задней части тела, зоны над 2-м рядом чешуй выше боковой линии и зоны ниже боковой линии над 3-м рядом чешуй (см. табл. 1). Однако все они статистически недостоверны по критерию Стьюдента, что позволяет предполагать, что исследованные рыбы относятся к одной популяции.

Ряды пятен. Пятна располагаются между рядами чешуй, в связи с чем они у большинства обследованных рыб сгруппированы в горизонтальные ряды (табл. 2). Ряды пятен обычно находятся ниже боковой линии (под 1-5-м рядами чешуй ниже боковой линии); над ней (над 1-3-м рядами чешуй) они встречаются реже. «В боковой линии» пятна в виде рядов бывают редко, они обнаружены здесь всего у 10.1\% рыб (см. табл. 2).

Форма и размеры пятен разные, в том числе у одних и тех же рыб. Обычно форма пятен неправильная, близкая к округлой, овальной или треугольной (углом вверх или вниз). Реже встречаются s-, 2-образные и более сложные пятна (см. рис. 1,$2 ; 4)$.

Размеры пятен составляют около 0.2-0.5 диаметра чешуи, рядом с которой они располагаются. Изредка встречаются удлиненные, более крупные пятна, вытянутые как в горизонтальном, так и в вертикальном направлении, размером в 2-3 чешуи.

Количество пятен. Среднее количество пятен на боку обследованных рыб из р. Правая Бурея составило 9.6土 0.43 (1-29; рис. 3), из р. Левая Бурея - 9.7 \pm 0.84 (2-20; табл. 3). В целом - 9.73 \pm 0.39 .

По одному пятну было только у трех рыб из р. Правая Бурея. $\mathrm{y}$ этих особей единственное пятно располагалось у границы туловища с cleithrum ниже боковой линии под 2-м рядом че-

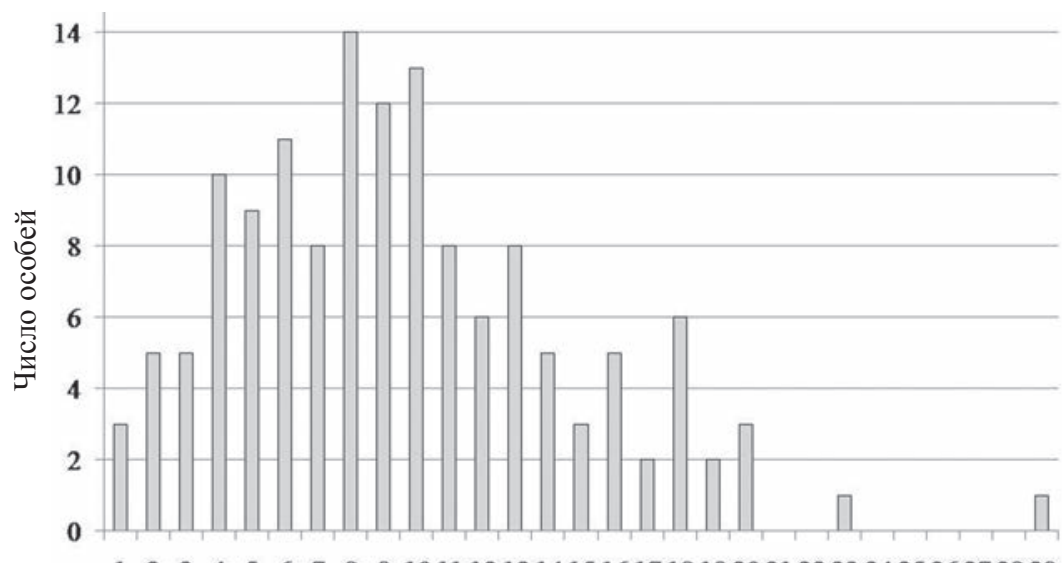

$\begin{array}{lllllllllll}1 & 2 & 3 & 4 & 5 & 6 & 7 & 8 & 9 & 1011 & 121314151617181920212223242526272829\end{array}$

Число пятен, шт.

Рис. 3. Распределение хариусов из р. Правая Бурея по количеству пятен $(\mathrm{n}=140)$

Fig. 3. Distribution of graylings from the Pravaya Bureya River by the number of spots $(n=140)$ 
ниже боковой линии (табл. 4). Всего в выборке из p. Правая Бурея с одним пятном на этом участке тела $(\mathrm{n}=132)$ обнаружено шесть его вариантов расположения (фенотипов), а в малочисленной выборке из р. Левая Бурея $(\mathrm{n}=25)$ - четыре (см. табл. 4). Показатель внутрипопуляционного разнообразия по этому признаку составил соответственно 3.72 и 3.24 , а доля редких морф 0.38 и 0.19 . Известно, что низкое значение этого показателя и, напротив, высокое доли редких морф свидетельствует о снижении фенотипического разнообразия и характерно для популяций, обитающих в условиях антропогенной трансформации местообитаний (Трофимов, 2008; Полетаев, 2014). Полученные значения позволяют заключить, что по анализируемому признаку внутрипопуляционное разнообразие в обеих реках достаточно высокое. Доля редких морф выше в р. Правая Бурея, что, вероятно, объясняется несколько более выраженным антропогенным воздействием на рыб в этой реке и, возможно, сравнительно низким уровнем разнообразия местообитаний. В целом полученные показатели разнообразия, возможно, могут быть использованы для мониторинговых исследований и для сравнения с рыбами, обитающими в других частях бассейна.

Возможность индивидуальной идентификации особей. Был также сделан анализ количества пятен и особенностей их расположения,

Таблица 3. Среднее число пятен и их рядов у рыб из рр. Правая и Левая Бурея

Table 3. Average number of spots and their rows in fishes from the Pravaya and the Levaya Bureya rivers

\begin{tabular}{|c|c|c|}
\hline \multirow{2}{*}{ Фенокомплекс } & \multicolumn{2}{|c|}{ Место отлова } \\
\hline & Правая Бурея, $\mathrm{n}=140$ & Левая Бурея, $\mathrm{n}=28$ \\
\hline \multicolumn{3}{|c|}{ 1. Количество пятен } \\
\hline Всего пятен & $9.5 \pm 0.4, \delta=51, \lim =1-29$ & $9.7 \pm 0.8, \delta=4.4, \lim =2-20$ \\
\hline «В боковой линии» & $1.5 \pm 0.1, \delta=1.6, \lim =0-4$ & $1.1 \pm 0.3, \delta=1.6, \lim =0-6$ \\
\hline $\begin{array}{l}\text { Выше боковой линии в 1-м } \\
\text { ряду }\end{array}$ & $2.4 \pm 0.1, \delta=1.6, \lim =0-6$ & $2.7 \pm 0.3, \delta=1.7, \lim =0-7$ \\
\hline $\begin{array}{l}\text { Выше боковой линии, } \\
\text { всего }\end{array}$ & $2.5 \pm 0.2, \delta=1.9, \lim =0-9$ & $2.9 \pm 0.4, \delta=1.9, \lim =1-12$ \\
\hline $\begin{array}{l}\text { Ниже боковой линии } \\
\text { в 1-м ряду }\end{array}$ & $2.7 \pm 0.2, \delta=1.7, \lim =0-8$ & $2.8 \pm 0.3, \delta=1.6, \lim =0-8$ \\
\hline $\begin{array}{l}\text { Ниже боковой линии во } \\
\text { 2-м ряду }\end{array}$ & $1.0 \pm 0, \delta=0.4, \lim =0-3$ & $1.1 \pm 0, \delta=0.8, \lim =0-3$ \\
\hline $\begin{array}{l}\text { Ниже боковой линии - } \\
\text { всего }\end{array}$ & $5.9 \pm 0.3, \delta=3.4, \lim =1-22$ & $5.6 \pm 0.5, \delta=2.9, \lim =1-12$ \\
\hline \multicolumn{3}{|c|}{ 2. Количество рядов пятен } \\
\hline Ниже боковой линии & $0.8 \pm 0.1, \delta=0.8, \lim =0-3$ & $0.8 \pm 0.1, \delta=0.7, \lim =0-2$ \\
\hline Выше боковой линии & $0.5 \pm 0.1, \delta=0.54, \lim =0-2$ & $0.5 \pm 0.1, \delta=0.5, \lim =0-1$ \\
\hline Всего рядов пятен & $1.4 \pm 0.1, \delta=1.3, \lim =0-5$ & $1.3 \pm 0.2, \delta=1.1, \lim =0-3$ \\
\hline
\end{tabular}

Таблица 4. Варианты расположения пятна у границы с cleithrum, показатель внутрипопуляционного разнообразия и доля редких морф у рыб, имеющих на этом участке одно пятно, в выборках из рр. Правая и Левая Бурея, \%

Table 4. Variants of the spot location near the border with cleithrum, intrapopulation diversity indicator, and rare morphs proportion in fish that with one spot in this section in samples from the Pravaya and the Levaya Bureya rivers, $\%$

\begin{tabular}{|l|c|c|c|}
\hline \multicolumn{1}{|c|}{ Варианты расположения (фенотипы) } & Правая Бурея, $\mathrm{n}=132$ & Левая Бурея, $\mathrm{n}=25$ & $\begin{array}{c}\text { В целом } \\
\mathrm{n}=157\end{array}$ \\
\hline Под 1-м рядом чешуй & 1.5 & 0 & 1,3 \\
\hline Под 2-м рядом чешуй & 64.4 & 68.0 & 65,0 \\
\hline Под 3-м рядом чешуй & 7.6 & 8.0 & 7,6 \\
\hline Между 1-м и 2-м рядом чешуй & 3.8 & 12.0 & 5.1 \\
\hline Между 1-м и 3-м (от 1-го до 3-го)* & 3.0 & 0 & 18.5 \\
\hline Между 2-м и 3-м (от 2-го до 3-го)* & 19.7 & 12.0 & - \\
\hline Показатель разнообразия & $3.72 \pm 0.25$ & $3.24 \pm 0.31$ & - \\
\hline Доля редких морф & $0.38 \pm 0.04$ & $0.19 \pm 0.08$ & \\
\hline
\end{tabular}

*В некоторых случаях пятно имело большие размеры и располагалось на этих участках. 


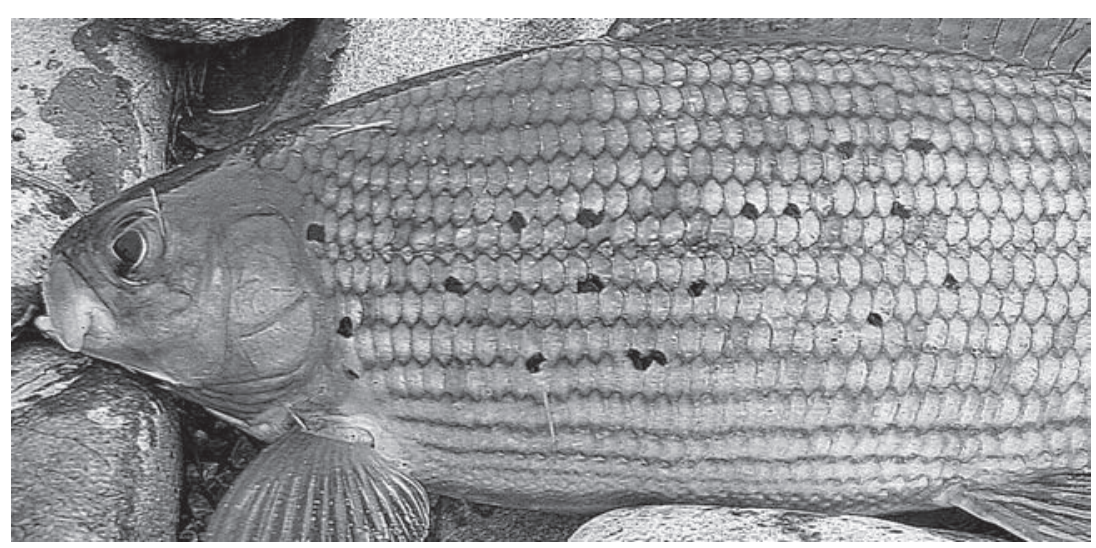

Puc. 4. У одних и тех же рыб пятна имеют разную форму и размеры

Fig. 4. In the same fish, spots have different shapes and sizes

формы и размеров у каждой особи, в том числе из нижерасположенных притоков р. Бурея. Установлено, что общее количество пятен у разных рыб может совпадать (см. рис. 3), но их расположение, форма и размеры при этом не совпадают. Хотя за весь период наблюдений не было отмечено ни одного повторного отлова сфотографированных рыб, это позволяет распознавать каждую особь.

Кроме этого, зафиксированы три случая, когда у части рыб, отловленных в одних местах (по 2-4 особи в каждом месте; расстояние между точками отлова этих особей составляло $1-5$ м) и в одно время (интервал отлова 0.5-20 мин), имеющих почти одинаковые размеры, характер расположения пятен, их форма и размеры были близкими, т. е. можно предполагать, что эти особи, скорее всего, являются родственниками.

\section{ЗАКЛЮЧЕНИЕ}

Таким образом, у всех обследованных представителей вида Thymallus burejensis пятна имеются на следующих участках тела: 1) в передней части; 2) позади головы близ cleithrumsupracleithrum; 3) ниже боковой линии. Из других фенокомплексов достаточно часто встречается комплекс, включающий пятна выше боковой линии (92.9\%). Общее количество пятен на левом боку рыб варьирует от 1 до 29, в среднем $9.7 \pm 0.39$. В случаях, если у рыб имеется небольшое количество пятен (1-2), они всегда расположены позади головы близ cleithrum ниже боковой линии. Форма и размеры пятен разнообразны; чаще они имеют неправильную форму, близкую к округлой. Вероятно, рыбы из pр. Правая и Левая Бурея составляют единую популяцию, о чем свидетельствует отсутствие статистически значимых различий между ними по анализируемым признакам. Эти характеристики можно принять в качестве исходных в мониторинговых исследованиях особенностей окраски данного вида.
Полученные результаты позволяют также заключить, что у буреинского хариуса этот фенокомплекс, т. е. расположение пятен, их размеры и форма, имеет индивидуальный характер, что дает возможность распознавать каждую особь и исследовать, например, миграции и перемещения, обосновывать выделение локальных популяционных и, возможно, близкородственных группировок без изъятия рыб. Это особенно важно в условиях Буреинского заповедника, охраняющего значительную часть ареала этого вида.

\section{БЛАГОДАРНОСТЬ}

Выражаю глубокую благодарность руководству Буреинского заповедника - А. Д. Думикяну, В. В. Турченко, М. Ф. Бисерову, И. А. Подолякину за помощь в организации экспедиций, а также инспекторам заповедника - В. П. Шичанину, Г. И. Таранику, П. Сарычеву, П. В. Лисиину за помощь в сборе материала.

\section{ЛИТЕРАТУРА}

Антонов А. Л. Новый вид хариуса Thymallus burejensis sp. nova (Thymallidae) из бассейна Амура // Вопросы ихтиологии. 2004. Т. 44, № 4. С. 441-451.

Антонов А. Л. Разнообразие рыб и структура ихтиоценозов горных водосборов бассейна Амура // Там же. 2012. Т. 52, № 2. С. 184-194.

Животовский Л. А. Показатель внутрипопуляционного разнообразия // Журнал общей биологии. 1980. T. 41, № 6. C. 828-836.

Животовский Л. А. Популяционная биометрия. Москва : Наука, 1991. 271 с.

Зиновьев Е. А., Богданов В. Д. Окраска и форма спинного плавника хариусов как диагностические признаки // Совр. пробл. зоологии и совершенствование ее преподавания в вузе и школе: тез. Всесоюз. конф. зоологов педвузов. Пермь, 1976. С. 254-256.

Книжин И. Б., Вайс С. Дж., Антонов А. Л., Фруфe Э. Морфологическое и генетическое разнообразие амурских хариусов (Thymallus, Thymallidae) // Вопросы ихтиологии. 2004. Т. 44, № 1. С. 59-76.

Макоедов A. H. Межпопуляционные различия и история расселения хариусов Thymallus: исследование изменчивости окраски спинного плавника // Там же. 1987. Вып. 6. С. 906-912.

Макоедов А. Н. Родственные отношения хариусов Сибири и Дальнего Востока. Москва : ЧукотТИНРО, 1999. 108 c.

Полетаев А. С. Сравнение фенотипических особенностей речного окуня (Perca fluviatilis L., 1758) различных водных объектов Минской области Республики Беларусь и предполагаемые факторы, влияющие на изменчивость его криптической окраски // Тр. БГУ. 2014. Т. 9, Ч. 2. С. $143-150$. 
Пресноводные рыбы Анадырского бассейна / И. А. Черешнев, А. В. Шестаков, М. Б. Скопец, Ю. А. Коротаев, А. Н. Макоедов. Владивосток : Дальнаука, 2001. $336 \mathrm{c}$.

Пустовойт С. П. Фенетическое разнообразие восточно-сибирского хариуса Thymallus arcticus pallasii Valenciennes верхнего течения реки Колымы // Сибирский экологический журнал. 2008. № 1. C. 71-75.

Романов В. И., Лаврентьев С. Ю., Дылдин Ю. В. К морфологии сибирского хариуса Thymallus arcticus (Pallas) из бассейна реки Казым (Нижняя Обь) // Вестник Сургут. гос. ун-та. 2016. Вып. 3 (13). С. 37-42.
Световидов А. Н. Европейско-азиатские хариусы (Genus Thymallus Cuvier) // Тр. Зоол. ин-та АН СССР. 1936. T. 3. С. 183-301.

Трофимов И. Е. Некоторые результаты популяционно-фенетического анализа Nicrophorus vespillo (Coleoptera, Silphidae) из калужского городского бора // Зоологический журнал. 2008. Т. 87, № 6. C. 658-664.

Яблоков А. В. Фенетика. Москва : Наука, 1980. $132 \mathrm{c}$.

Яблоков А. В., Ларина Н. И. Введение в фенетику популяций. Новый подход к изучению природных популяций. Москва : Высш. шк., 1985. 159 с.

Поступила в редакиию 26.11.2019 2.

Поступила после доработки 11.12.2019 г.

\title{
PHENETIC FEATURES OF THE BUREYA GRAYLING THYMALLUS BUREJENSIS (SALMONIDAE): BLACK SPOTS ON THE BODY SIDES
}

\author{
A. L. Antonov
}

\author{
Institute of Water and Ecological Problems of the FEB RAS, Khabarovsk
}

\begin{abstract}
The coloration features of the body of the Bureya grayling Thymallus burejensis (black spots on the left side of the fish) were studied. For the first time, data were obtained on the frequency of occurrence of spots and horizontal rows of spots in various parts of the body; the shape of the spots, their size and number were investigated. In total, 168 individuals from the rivers of the Bureinsky State Nature Reserve (140 from the Pravaya Bureya River and 28 from the Levaya Bureya River, after photographing over $90 \%$ of the fish were released) and 19 from other tributaries of the Bureya River were analyzed by color photographs. In all fish, spots were found 1) in the front of the body; 2) behind the head near cleithrum-supracleithrum; 3) below the lateral line. The total number of spots on the side averaged 9.6 $\pm 0.4(\mathrm{lim}=1-29)$ in fish from the Right Bureya River, and -9.7 $\pm 0.8(\mathrm{lim}=2-20)$ in those from the Left Bureya River. It is assumed that individuals from these rivers represent a single population, since no statistically significant differences between them in the analyzed phenes and phenocomplexes were found. It was also established that the number of spots in different individuals may coincide, but the features of their location, size, and shape are individual. This, under the conditions of the conservation regime, allows each individual to be identified without being removed from nature, which is important for studies of seasonal migrations, movements, and segregation of local population groups.
\end{abstract}

Keywords: Bureya grayling Thymallus burejensis, phenetics, black spots, Bureya River basin.

\section{REFERENCES}

Antonov, A. L., 2004. New Species of Grayling Thymallus burejensis sp. nova (Thymallidae) from the Amur Basin, Voprosy Ikhtiologii. 44, 4, 441-451 [In Russian].

Antonov, A. L., 2012. Fish Diversity and Ichthyocenoses Structure in Mountain Catchment Areas of the Amur Basin, Ibid. 52, 2, 184-194 [In Russian].

Freshwater Fishes of the Anadyr Drainage, Chereshnev I. A., Shestakov A. V., Skopets M. B., Korotayev Yu. A., Makoyedov A. N., 2001. Vladivostok, Dal'nauka [In Russian].

Knizhin, I. B., Weiss, S. J., Antonov, A. L., Frufe, E., 2004. Morphological and Genetic Diversity of Amur Grayling (Thymallus, Thymallidae), Voprosy Ikhtiologii. 44, 1, 59-76 [In Russian].
Makoyedov, A. N., 1987. Interpopulation Differences and the History of the Thymallus Grayling Distribution: Study of Color Variability of the Dorsal Fin, Voprosy Ikhtiologii. 6, 906-912 [In Russian].

Makoyedov, A. N., 1999. Kinship between Graylings of Siberia and of the Far East. Moscow, ChukotTINRO [In Russian].

Poletayev, A. S., 2014. Comparison of the Phenotypic Characteristics of River Perch (Perca fluviatilis L., 1758) from Various Water Bodies of the Minsk Oblast, Republic of Belarus, and Assumed Factors Affecting Variability of Its Cryptic Coloration, Proceedings of the Belarusian State University. 9, 2, 143-150 [In Russian].

Pustovoit, S. P., 2008. Phenetic Diversity of the East Siberian Grayling Thymallus arcticus pallasii Valenci- 
ennes of the Upper Kolyma River, Contemporary Problems of Ecology. 1, 71-75 [In Russian].

Romanov, V. I., Lavrentiev, S. Yu., Dyldin, Yu. V., 2016. On the Morphology of the Siberian Grayling Thymallus arcticus (Pallas) from the Kazym River Basin (Lower Ob), Surgut State University Journal. 3 (13), 37-42 [In Russian].

Svetovidov, A. N., 1936. Euro-Asian Grayling (Genus Thymallus Cuvier), Trudy Zoologicheskogo Instituta Academii Nauk SSSR. 3, 183-301 [In Russian].

Trofimov, I. E., 2008. Some Results of a PopulationPhenetic Analysis of Nicrophorus vespillo (Coleoptera, Silphidae) from the Kaluga Urban Forest, Zoologicheskii Zhurnal. 87, 6, 658-664 [In Russian].

Yablokov, A. V., 1980. Phenetics. Moscow, Nauka [In Russian].
Yablokov, A.V., Larina, N. I., 1985. Introduction to the Phenetics of Populations. A New Approach to the Study of Natural Populations. Moscow, Vysshaya Shkola [In Russian].

Zhivotovsky, L. A., 1980. The Indicator of Intrapopulation Diversity, Zhurnal Obshchei Biologii. 41, 6, 828836 [In Russian].

Zhivotovsky, L. A., 1991. Population Biometrics. Moscow, Nauka [In Russian].

Zinoviev, E. A., Bogdanov, V. D., 1976. Coloration and form of the Dorsal Fin of Grayling as Diagnostic Signs, Modern Prob. Zoology and the Improvement of Its Teaching at the University and School, Abstracts of All-Union Conference of Zoologists from Pedagogic Universities. 254-256 [In Russian]. 